\title{
The effect of acetic acid on the structure and filtration properties of poly(vinyl alcohol) membranes
}

\author{
Wen-Yuan Chuang ${ }^{a}$, Tai-Horng Young ${ }^{b, *}$, Wen-Yen Chiu ${ }^{a}$ \\ a Institute of Materials Science and Engineering, College of Engineering, National Taiwan University, Taipei, Taiwan \\ ${ }^{\mathrm{b}}$ Institute of Biomedical Engineering, College of Medicine and College of Engineering, National Taiwan University, Taipei, Taiwan
}

Received 11 November 1999; received in revised form 27 January 2000; accepted 27 January 2000

\begin{abstract}
The role played by acetic acid in the formation of poly(vinyl alcohol) (PVA) membranes was investigated. Membranes were prepared from a casting solution of PVA, water, and acetic acid by immersion in $\mathrm{Na}_{2} \mathrm{SO}_{4} / \mathrm{KOH} / \mathrm{H}_{2} \mathrm{O}$ coagulation bath. Experimental results show that the acetic acid additive exerts an influence on the structure and filtration properties of membranes. Not only the surface morphology but also the structure of cross-section could be modulated by adding the acetic acid in the casting solution. Obviously, the increase of the amount of acetic acid in the casting solution decreased the thickness of skin layer. This could be attributed to the fact that the increase of the amount of acetic acid in the casting solution increases $\mathrm{H}_{3} \mathrm{O}^{+}$ion of the casting solution enhancing the influx rate of coagulant medium for acid-base equilibrium. A mechanism describing the affinity between the PVA solution and the coagulant medium is proposed to estimate the PVA membrane structure by adding the acid. The results presented here offer a better understanding of relationships between the membrane formation mechanism and the skin structure when designing an asymmetric membrane with acetic acid as an additive. (c) 2000 Elsevier Science B.V. All rights reserved.
\end{abstract}

Keywords: Poly(vinylalcohol); Asymmetric membrane; Acetic acid

\section{Introduction}

Since the development of asymmetric type membrane by Loeb and Sourirajan [1], considerable progress has been made in various aspects of membrane related fields [2]. The interest in studies of membranes is due to the necessity of membranes with different separation properties. An asymmetrical membrane is characterized by a thin and dense top layer, commonly recognized as the skin layer, and

\footnotetext{
* Corresponding author. Tel.: +886-2-23970800/ext. 1455; fax: +886-2-23940049.

E-mail address: thyoung@ha.mc.ntu.edu.tw (T.-H. Young)
}

underneath which is a porous solid matrix. It is well known that the skin layer provides major resistance to the permeation of solute through the membrane whereas the porous region functions exclusively as a mechanical support. The capability of an asymmetric membrane to reject or admit a certain solute species is, therefore, determined by the morphology, the pore size and density of the skin layer. Accordingly, it is necessary to prepare asymmetric membranes with controllable structure of skin layer to achieve the required performance in the membrane.

Poly(vinyl alcohol) (PVA) was a typical semicrystalline polymer, and many studies have been carried out on aqueous PVA gels. Recently, the PVA 
membranes were coagulated with $\mathrm{Na}_{2} \mathrm{SO}_{4} / \mathrm{KOH} / \mathrm{H}_{2} \mathrm{O}$ bath by Young et al. $[3,4]$ to form an asymmetric membrane. Being a material with good chemical stability, thermal stability and high water permeability, PVA seems an attractive material for producing membranes [5]. In order to control the membrane structure, low molecular weight component or the secondary polymer is frequently used as the additive in the membrane forming system [6] because it offers a convenient and effective way to develop membranes with high performances. A very important controllable factor was the addition of another low molecular weight component to the polymer solution to change the diffusion rate of solvent/coagulant medium. In this present work, acetic acid was used as low molecular weight component to control the membrane structure. A series of asymmetric membranes were prepared by adding acetic acid to the polymer solution. Therefore, the aim of this study was to get a better understanding of the PVA membrane formation process by adding the acetic acid in the polymer solution on SEM observations.

\section{Experimental}

\subsection{Materials}

All reagents in the study were of reagent grade, unless otherwise described. The membrane materials, PVA with average molecular weight $74,800 \mathrm{~g} / \mathrm{mol}$ was used in this study supplied by Chang Chun (Taiwan).
Acetic acid of LC grade was purchased from ALPS Chem. Water was double distilled and deionized before used.

\subsection{Membrane preparation}

Membranes were prepared by the immersionprecipitation technique. The compositions of PVA casting solution, the components of coagulation bath, the process of membranes preparation, figure number and the morphology of that membrane are listed in Table 1. The water was the solvent for PVA and the acetic acid played an important rule to control the membrane structure. These different composition of casting solution was dissolved at $90^{\circ} \mathrm{C}$ to form a homogeneous solution. Then the polymer solution at $25^{\circ} \mathrm{C}$ was coated on a glass plate to a uniform thickness of about $100 \mu \mathrm{m}$. Finally, the glass plate and coated solution were immersed into a coagulation bath [5], water, containing $75 \mathrm{~g} / \mathrm{l}$ of $\mathrm{KOH}$ was saturated with $\mathrm{Na}_{2} \mathrm{SO}_{4}$ to obtain a uniform membrane. The morphology of the membranes was examined using a scanning electron microscope (SEM) after freeze-dried.

\subsection{Pure water and dextran filtration}

Pure water flux and solute rejection were determined using a $43 \mathrm{~mm}$ diam Amicon stirred ultrafiltration cell (Model 8050) at a stirring speed of $600 \mathrm{rpm}[7,8]$. The solutes used in this work were

Table 1

The compositions of PVA solution, the components of coagulation bath, the process of membranes preparation, figure number and the morphology of that membrane

\begin{tabular}{|c|c|c|c|c|c|c|c|c|c|}
\hline \multirow[t]{2}{*}{ Membrane } & \multicolumn{4}{|c|}{ Composition of PVA solution } & \multirow[t]{2}{*}{ Coagulation bath ${ }^{\mathrm{a}}$} & \multirow[t]{2}{*}{ Phase inversion } & \multirow[t]{2}{*}{ Figure numbers } & \multicolumn{2}{|l|}{ Morphology } \\
\hline & PVA (g) & $\mathrm{H}_{2} \mathrm{O}(\mathrm{g})$ & $\mathrm{HCl}(\mathrm{g})$ & Acetic acid (g) & & & & Skin layer & Sublayer \\
\hline M-1 & 1.4 & 8.6 & 0 & 0 & $\mathrm{Na}_{2} \mathrm{SO}_{4} / \mathrm{KOH} / \mathrm{H}_{2} \mathrm{O}$ & Wet process & Fig. 1 & Dense & Porous \\
\hline M-1B & 1.4 & 8.6 & 0 & 0 & $\mathrm{Na}_{2} \mathrm{SO}_{4} / \mathrm{H}_{2} \mathrm{O}$ & Wet process & Fig. 2 & Dense & Dense \\
\hline $\mathrm{H}-1$ & 1.4 & 8.6 & 2 & 0 & $\mathrm{Na}_{2} \mathrm{SO}_{4} / \mathrm{KOH} / \mathrm{H}_{2} \mathrm{O}$ & Wet process & Fig. 4 & Porous & Porous \\
\hline A-1 & 1.4 & 8.6 & 0 & 1 & $\mathrm{Na}_{2} \mathrm{SO}_{4} / \mathrm{KOH} / \mathrm{H}_{2} \mathrm{O}$ & Wet process & Fig 5a and Fig. 6a & Dense & Porous \\
\hline A-2 & 1.4 & 8.6 & 0 & 2 & $\mathrm{Na}_{2} \mathrm{SO}_{4} / \mathrm{KOH} / \mathrm{H}_{2} \mathrm{O}$ & Wet process & Fig. $5 b$ and Fig. $6 b$ & Thin, dense & Porous \\
\hline A-3 & 1.4 & 8.6 & 0 & 4 & $\mathrm{Na}_{2} \mathrm{SO}_{4} / \mathrm{KOH} / \mathrm{H}_{2} \mathrm{O}$ & Wet process & Fig. $5 c$ and Fig. $6 c$ & Thin, dense & Porous \\
\hline A-4 & 1.4 & 8.6 & 0 & 6 & $\mathrm{Na}_{2} \mathrm{SO}_{4} / \mathrm{KOH} / \mathrm{H}_{2} \mathrm{O}$ & Wet process & Fig. $5 d$ and Fig. $6 d$ & Porous & Porous \\
\hline L-1 & 0.7 & 9.3 & 0 & 0 & $\mathrm{Na}_{2} \mathrm{SO}_{4} / \mathrm{KOH} / \mathrm{H}_{2} \mathrm{O}$ & Wet process & Fig. 10 & Dense & Porous \\
\hline
\end{tabular}

${ }^{a}$ The composition of $\mathrm{Na}_{2} \mathrm{SO}_{4} / \mathrm{KOH} / \mathrm{H}_{2} \mathrm{O}$ represents the coagulation bath, water, containing $75 \mathrm{~g} / \mathrm{l}$ of $\mathrm{KOH}$ was saturated with approximate $249 \mathrm{~g} / \mathrm{l}$ of $\mathrm{Na}_{2} \mathrm{SO}_{4}$; the composition of $\mathrm{Na}_{2} \mathrm{SO}_{4} / \mathrm{H}_{2} \mathrm{O}$ represents the coagulation bath, water, was only saturated with approximate $240 \mathrm{~g} / \mathrm{l}$ of $\mathrm{Na}_{2} \mathrm{SO}_{4}$. 
commercial dextran fractions with average molecular weights $(\mathrm{g} / \mathrm{mol})$ of $6000(6 \mathrm{~K}), 12,42,71.4$, and $505 \mathrm{~K}$. The $6 \mathrm{~K}$-dextran sample was purchased from Fluka and the other dextran samples were purchased from Sigma. The feed solutions were prepared by dissolving dextrans in distilled deionized water. These solutions were agitated for $24 \mathrm{~h}$ to insure complete dissolution. For all filtration experiments, the concentration of solute in the feed was taken to be $1000 \mathrm{ppm}$ and the temperature was kept at $20 \pm 3^{\circ} \mathrm{C}$. A compressed nitrogen gas tank connected to the filtration cell was used as the pressure source. The transmembrane pressure was employed under a low pressure of $0.2 \mathrm{kgf} / \mathrm{cm}^{2}$ to minimize the effect of concentration polarization [7,8] for pure water flux and solute rejection experiments. To check whether the membrane has any defect, a solution containing $100 \mathrm{ppm}$ blue dextran was used as the feed. The average molecular weight of this blue dextran was $2000 \mathrm{~K}$ (Sigma). All tested membranes were found to reject the passage of blue dextran. After the permeating flux reaches a stable constant value (ca. $30 \mathrm{~min}$ after operation), samples of permeate were collected for subsequent chromatographic analysis by gel permeation chromatography (GPC) using a Waters 510 pump (USA) coupled with Ultrahydrogel SEC columns and a Waters 410 refractive index detector. The experimentally obtained rejection, $R$, is defined as $R=\left(C_{\mathrm{b}}-C_{\mathrm{p}}\right) / C_{\mathrm{b}}$, where $C_{\mathrm{b}}$ and $C_{\mathrm{p}}$ denote the concentrations of solute in the feed and permeate, respectively.

\subsection{Light transmission experiment}

Light transmission experiments were performed to measure the precipitation rate of the immersionprecipitation process. The principle of light transmission experiments is that the light transmittance of the casting solution would decrease with the appearance of optical inhomogeneous. Therefore, the time that the light transmittance begins to drop can be used to represent the time of the onset of precipitation [9]. To carry out the light transmission experiment, an UV-lamp observed the green light source at $520 \mathrm{~nm}$ was placed above the coagulation bath as light source and a light detector beneath the coagulation bath was used to measure the light transmittance. For detailed experimental set-up and procedures, one can refer to the work of Reuvers [10]. (a)

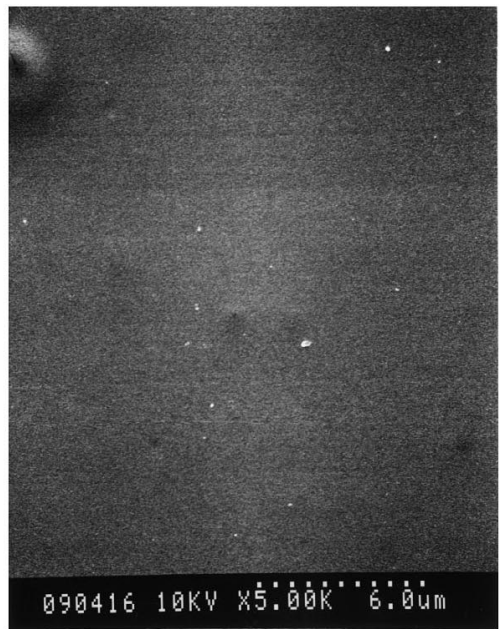

(b)

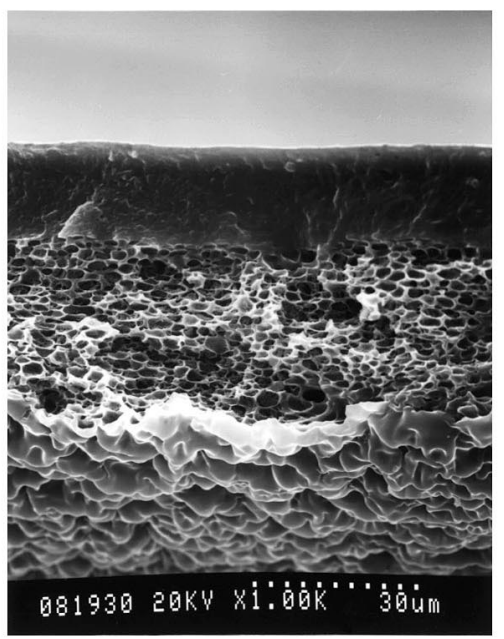

Fig. 1. The SEM photographs of M-1 membrane: (a) top (b) cross-section.

\section{Results and discussion}

\subsection{Membrane formation without acid}

Macroscopically, all membranes prepared were opaque in their appearance. Fig. 1 shows the SEM photographs of M-1 membrane. The membrane was prepared from $14 \mathrm{wt} . \%$ of PVA solution in the absence of acid. As shown in Fig. 1, the M-1 membrane was divided into two layers: toplayer and sublayer. It was shown a dense skin without any pores, which was supported by the porous sublayer with significant 
pores. The skin layer is responsible for the permeation or rejection of solutes whereas the porous sublayer acts only as a mechanical support.

In order to understand the effect of coagulant bath with $\mathrm{Na}_{2} \mathrm{SO}_{4} / \mathrm{KOH} / \mathrm{H}_{2} \mathrm{O}$ on the membrane formation process, the coagulant bath in which water was only saturated with $\mathrm{Na}_{2} \mathrm{SO}_{4}$ was used to investigate the M-1 membrane formation. Therefore, the M-1B membrane was prepared by the same procedure but with a different coagulant bath as indicated in Table 1, resulting in the formation of a dense sublayer without any pores as illustrated in Fig. 2. Compared to the M-1 membrane, the dense morphology of sublayer in M-1B membrane

(a)

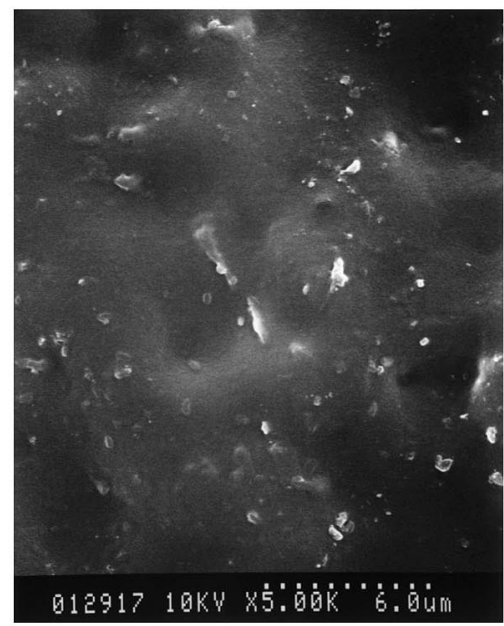

(b)

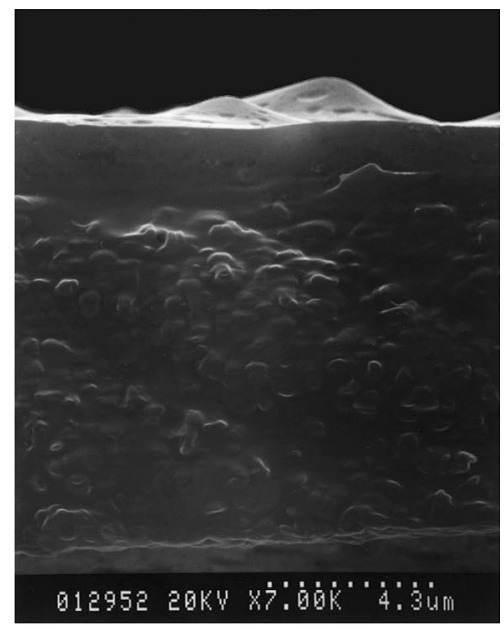

Fig. 2. The SEM photographs of M-1B membrane: (a) top (b) cross-section. is different from the porous sublayer of M-1 membrane. This is probably due to the salt effect of the aqueous solution of sodium sulfate with high concentration of ions, which caused the desolving of water from the casting solution and its continual outflow into the coagulant bath. This means that the local polymer concentration increased due to the salt effect. Consequently, the increase in polymer concentration caused by the outflow of water from the casting solution resulted in the formation of the dense structure as displayed by the M-1B membrane. Apparently, the result of SEM observation suggests that the absence of potassium hydroxide in the coagulant bath could form the dense sublayer. The result could be caused by the water from the sublayer through the skin diffusing into coagulant medium continuously due to the absence of $\mathrm{KOH}$ in the coagulation bath slow down the coagulant medium inflow to reduce the phase separation to form the dense sublayer.

In addition, the effect of the coagulant bath with $\mathrm{Na}_{2} \mathrm{SO}_{4} / \mathrm{KOH} / \mathrm{H}_{2} \mathrm{O}$ or with $\mathrm{Na}_{2} \mathrm{SO}_{4} / \mathrm{H}_{2} \mathrm{O}$ is evaluated during PVA membrane formation by precipitation method. In the Fig. 3, for each profile, the time at which light intensity begins to decrease is identified as the onset point of precipitation. It appears that so-called delayed precipitation took place in both of the cases. This result implies that the exchange rate between the coagulant medium and the water in the casting solution was slow in the coagulant bath. Clearly, the absence of potassium hydroxide in the coagulation bath causes a reduction in the precipitation rate resulted in the formation of the dense sublayer as shown in Fig. 2b. In contrast, the presence of potassium hydroxide enhances the influx rate of coagulant medium to cause an increase in the precipitation rate to reveal the porous sublayer of M-1 membrane. Therefore, in order to control the influx rate of coagulant medium and modulate the membrane structure, the addition of acid in the casting solution is prepared.

\subsection{Effect of hydrogen chloride}

Some investigators had reported that membrane structure may be regulated by increasing the evaporation time before immersing the casting solution in the coagulant bath [11], or by adding solvent or salt in the coagulant bath $[12,13]$. One of these methods is the addition of the low molecular weight component 


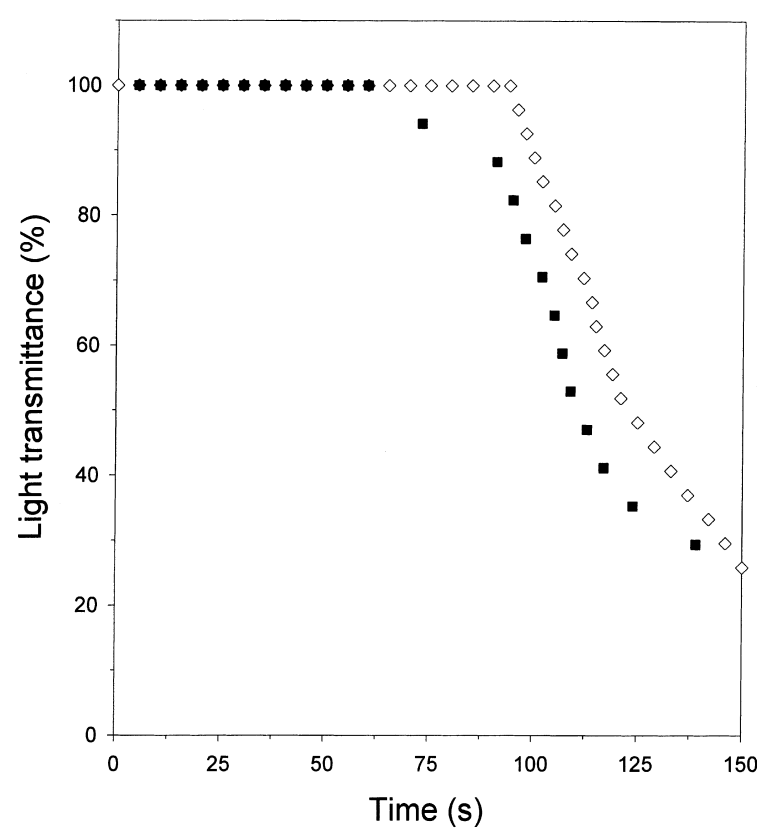

Fig. 3. The results of light transmission experiments of PVA membranes at the different composition of coagulant bath. ( $\square$ ) the coagulant, water, containing $75 \mathrm{~g} / \mathrm{l}$ of $\mathrm{KOH}$ was saturated with $\mathrm{Na}_{2} \mathrm{SO}_{4}(\diamond)$ The coagulant, water, was only saturated with $\mathrm{Na}_{2} \mathrm{SO}_{4}$.

to the casting solution. In order to modulate the membrane structure, the addition of acid in the casting solution is prepared to hasten the coagulant medium inflow due to the present of strong base (potassium hydroxide) in the coagulant bath. Firstly, the hydrogen chloride $(\mathrm{HCl})$ adds into the casting solution to change the membrane formation process. After the $\mathrm{HCl}$ adds into casting solution, it can be observed that the pores occur in the skin layer of $\mathrm{H}-1$ membrane (Fig. 4). It should be noted that the dense skin layer disappears by adding $20 \mathrm{wt} . \%$ of $\mathrm{HCl}$.

The simplest acid-base equilibrium are those in which a strong acid (or base) is dissolved in water. Consequently, the concentration of $\mathrm{H}_{3} \mathrm{O}^{+}$ion increases by adding the strong acid $(\mathrm{HCl})$ in the casting solution due to the presence of water. The $\mathrm{H}_{3} \mathrm{O}^{+}$ions in the casting solution can enhance in influx of the coagulant medium, which contains a base $(\mathrm{KOH})$ for acid-base equilibrium. However, the inflow of coagulant medium induced by the use of a strong acid such as $\mathrm{HCl}$ especially at high concentration, was too fast

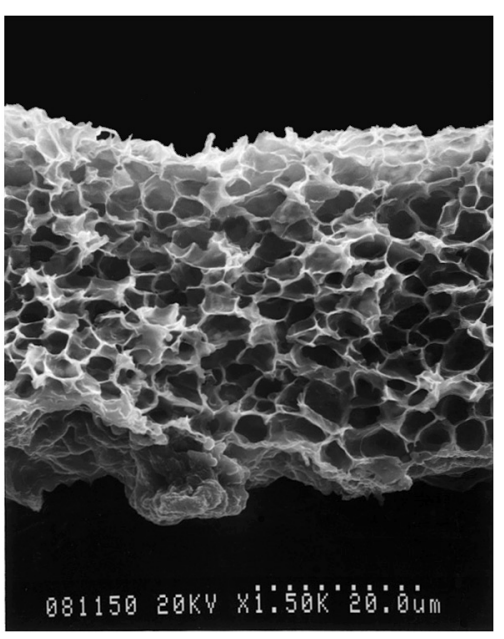

Fig. 4. The SEM photographs of cross-section of H-1 membrane.

such that the separation skin layer was completely destroyed as shown in Fig. 4. Instead, the use of a weaker acid, acetic acid in the casting solution was attempted in order to control the rate of coagulant medium inflow.

\subsection{Effect of acetic acid}

In Figs. 5 and 6, the SEM pictures reveal that the acetic acid content exerts an influence upon the structure of membranes. The results show that the thickness of skin layer decreased and the porosity increased with the increase of the amount of acetic acid in the casting solution as revealed in Fig. 6. Obviously, acetic acid additive is effective to induce pore formation in the skin layer. This can be explained by the fact that the presence of acetic acid changes the membrane formation mechanism. The concentration of $\mathrm{H}_{3} \mathrm{O}^{+}$ion also increases by adding the acetic acid in the casting solution. Thus, the acetic acid additive is believed to increase the influx rate of the coagulant medium for acid-base equilibrium as the $\mathrm{HCl}$ additive does. Especially, pores occur on the top surface of A-4 membrane as shown in Fig. 5d and the skin layer disappears as illustrated in Fig. 6d. This result clearly demonstrates that the skin layer is almost disappearing by adding the $60 \mathrm{wt} . \%$ of acetic acid into polymer solution. Therefore, the addition of acetic acid in the casting solution can prepare asymmetric membranes with controllable 


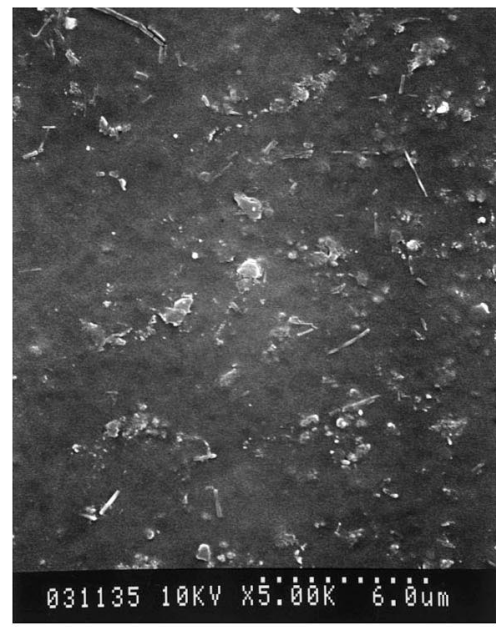

(a)

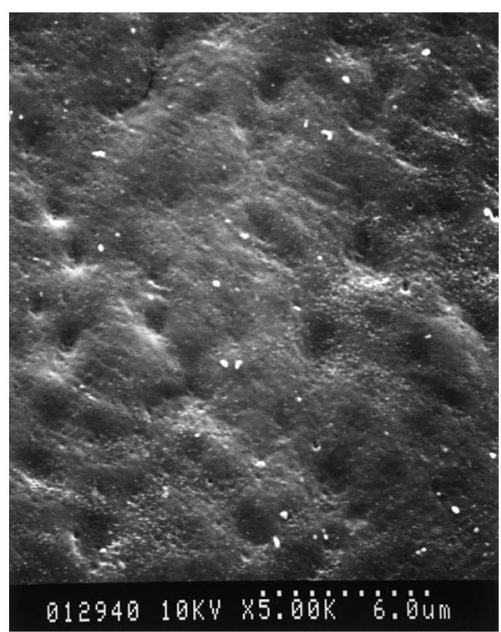

(b)

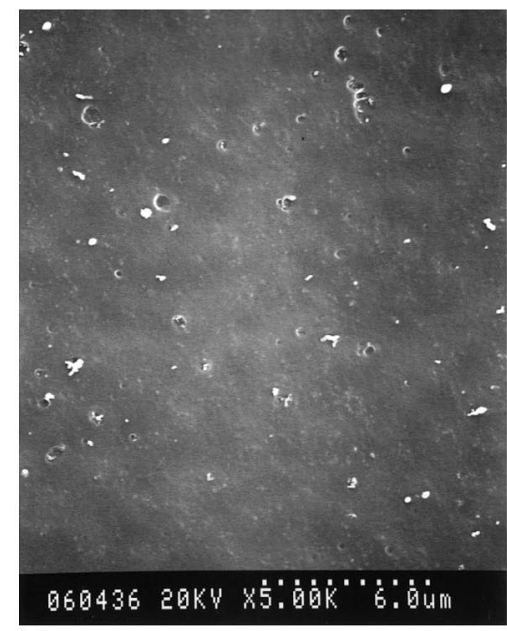

(c)

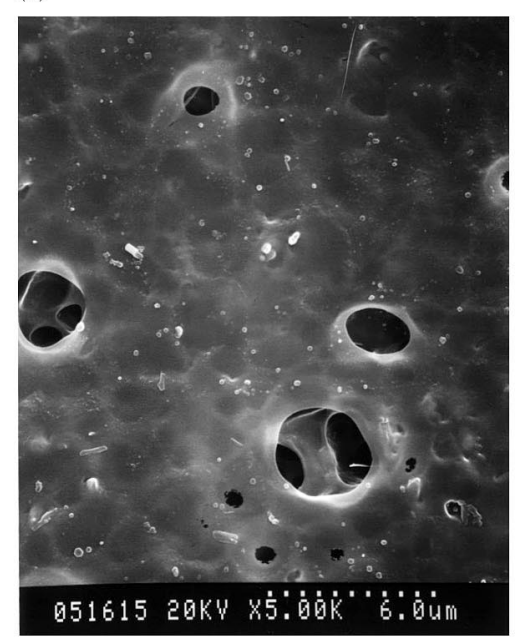

(d)

Fig. 5. The SEM photographs of top surface: (a) A-1 (b) A-2 (c) A-3 (d) A-4 membrane.

structure of skin layer to achieve the required performance in the membrane.

In order to estimate the performance of PVA membranes having a molecular sieve effect, ultrafiltration of pure water and a dextran solution having various molecular weight dextrans in the range of $6 \times 10^{3}-2 \times 10^{6}$ through the membranes was carried out. The pure water fluxes at the pressure of $0.2 \mathrm{kgf} / \mathrm{cm}^{2}$ for those PVA membranes are shown in Fig. 7. The water flux increased with the increase in the amount of acetic acid in the casting solution. Since these membranes have a similar interior structure, the thickness of the skin layer and how tightly this layer is packed dictate their water permeability. The results also reveal that the A-4 membrane with skinless toplayer has highest water flux than other membranes. Fig. 8 shows the rejection (or permeation) behavior of PVA membranes with and without acetic acid additive. It can be observed that the rejection increased monotonically with the molecular weight of the solute, as in ordinary filtration processes. In addition, the rejection curves markedly shift towards a high molecular weight side of dextran, when the amounts of the acetic acid in the casting solution increase. 


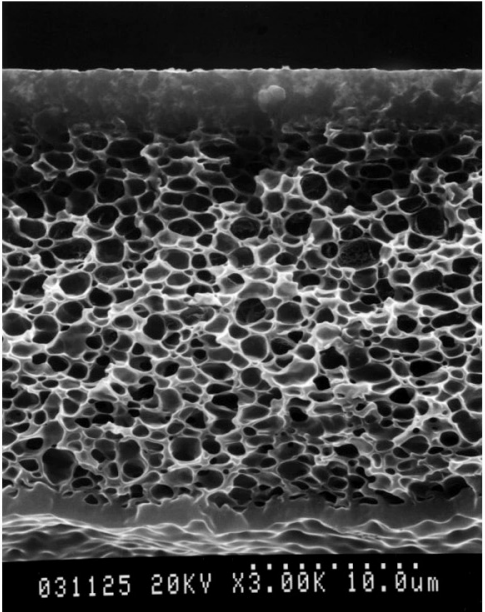

(a)

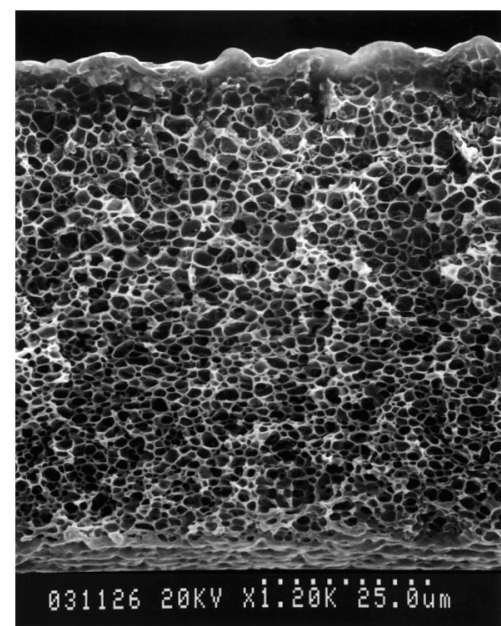

(b)

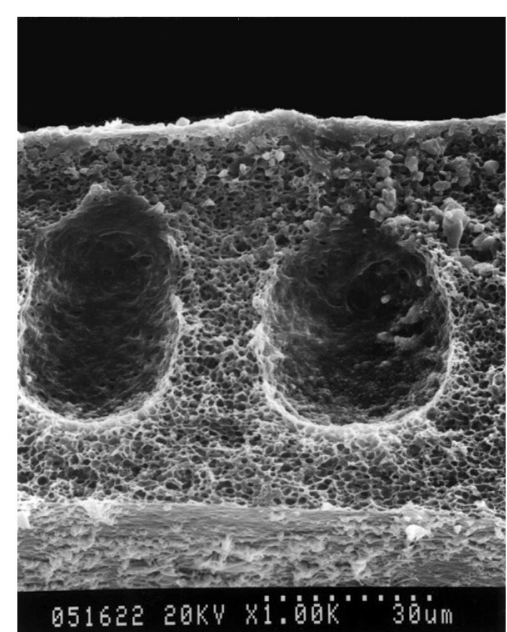

(c)

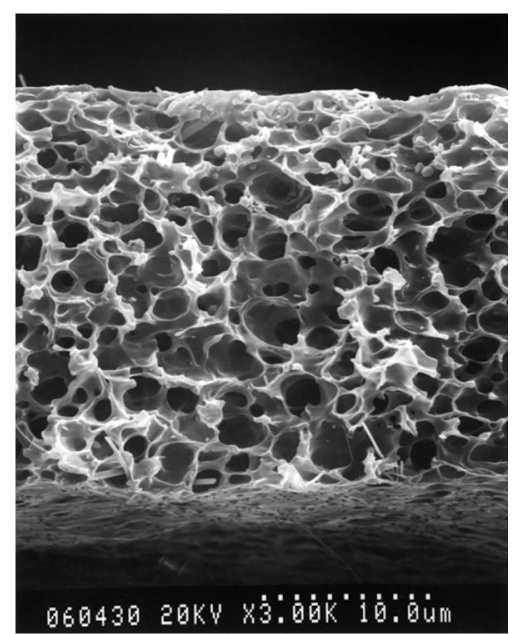

(d)

Fig. 6. The SEM photographs of cross-section: (a) A-1 (b) A-2 (c) A-3 (d) A-4 membrane.

In recent publications of Balmann and Nobrega [14] and Mochizuki and Zydney [15], a similar result was reported for the filtration of dextran through polysulfone and polyethersulfone membranes. The result of ultrafiltration is consistent with qualitative observations of SEM, suggesting that the acetic acid play a role of a pore former in the skin layer to increase permeability of PVA membranes. On basis of above observation, it can be concluded that the acetic acid exerts an influence on the structure and permeability of PVA membranes.
Another interesting characteristic of the effect of acid additive is the precipitation rate during membrane formation. The results are different as shown in Fig. 9. For each profile, the time at which light intensity begins to decrease is identified as the onset point of precipitation as described above. It appears that the so-called delayed precipitation took place in all of the immersion cases, which is similar to the case mentioned above. This implies that the exchange rate between the coagulant and the solvent is slow in the coagulation bath. Further, the addition of $\mathrm{HCl}$ or 


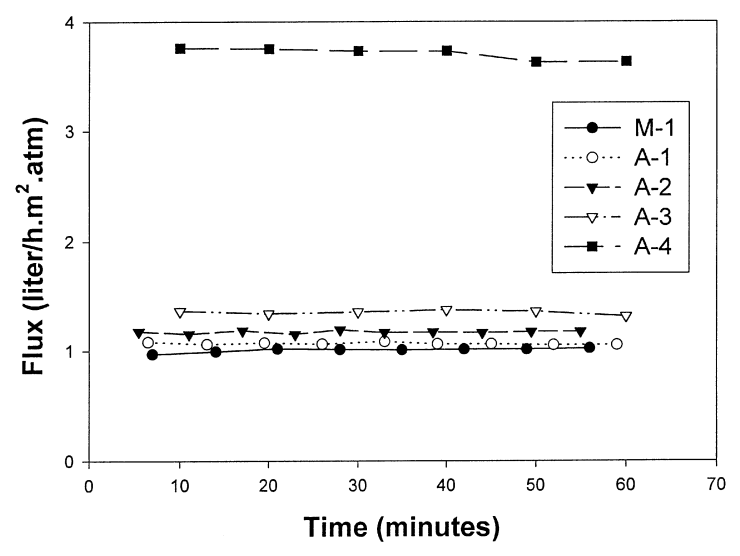

Fig. 7. Influence of acetic acid content of the polymer solution on the water flux of PVA membrane at the operating pressure of $0.2 \mathrm{kgf} / \mathrm{cm}^{2}$.

acetic acid in the casting solution causes an enhancement in precipitating rate. Especially, the strong acid $(\mathrm{HCl})$ with rich $\mathrm{H}_{3} \mathrm{O}^{+}$ion in the casting solution has the higher precipitation rate than the weak acid (acetic acid). In addition, the measurement of light transmission also indicates that the precipitation rate increases with an increase in the amount of acetic acid in the

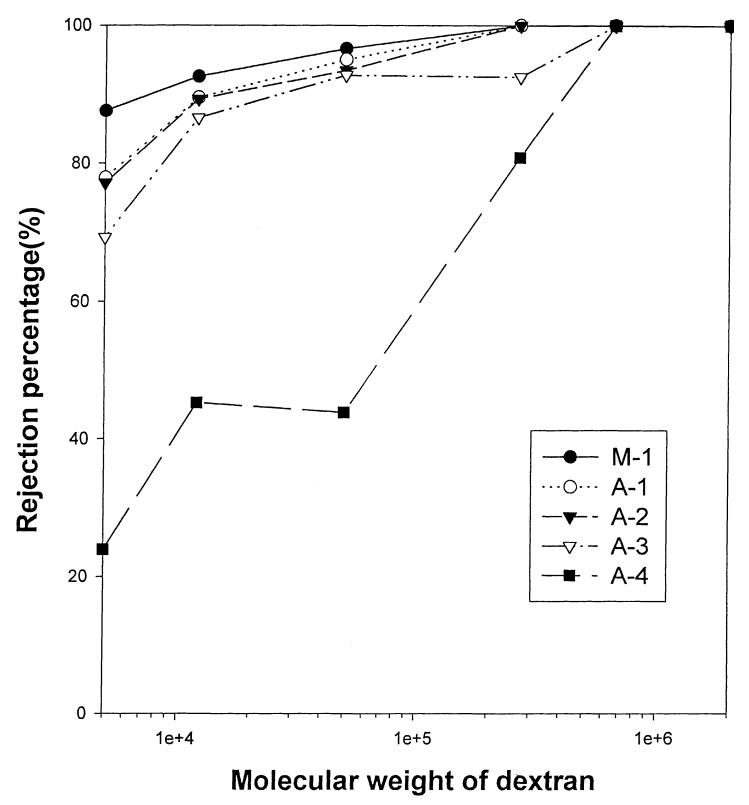

Fig. 8. The rejection percentage of dextran with different molecular weight $(5,12,50,270,670$, and $2000 \mathrm{~K})$ at the PVA membranes.

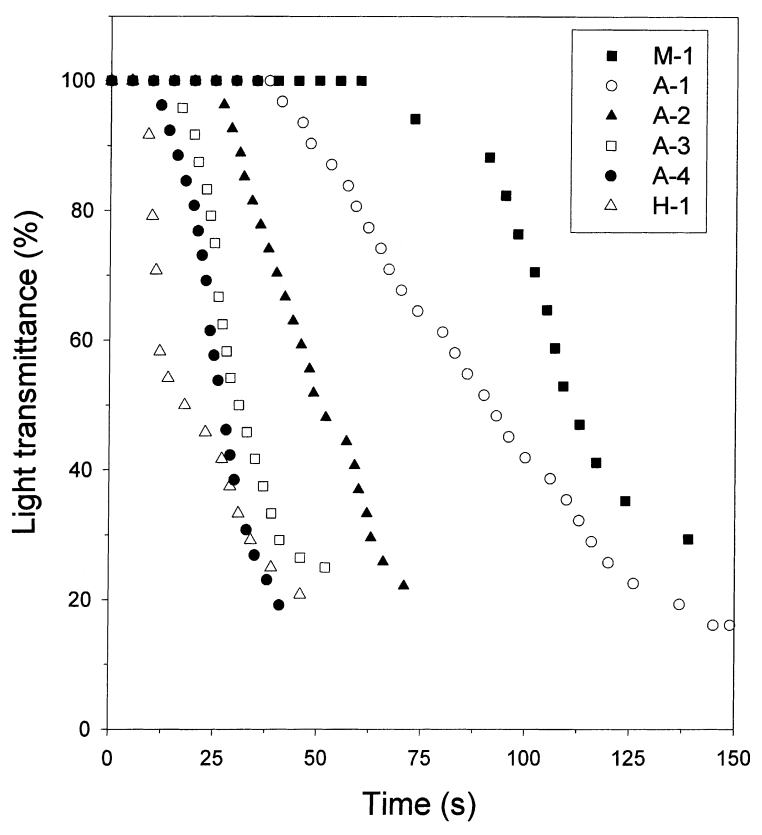

Fig. 9. The results of light transmission experiments of PVA membranes with different composition at the casting solution.

system. This means that the PVA membrane with an increase of acetic acid additive in the casting solution has a tendency toward forming large pores as reported by Lai et al. [9]. This can be related to the effect of the acid on the diffusibility of coagulant medium in polymer solution $[12,16]$ and thus on the membrane formation mechanism, as will be explained in the next.

Interestingly, it is conceivable that the acetic acid adds into the casting solution, the concentration of polymer solution is decreased. Apparently, when the acetic acid is as the solvent, the composition of A-4 solution is $8.75 \mathrm{wt} . \%$ of PVA solution. Therefore, the L-1 membrane with $7 \mathrm{wt}$.\% of PVA solution is prepared to compare with A-4 membrane. Fig. 10 shown that the L-1 membrane is clearly divided into two layers: toplayer and sublayer. It is shown a dense skin without any pores, which is supported by the porous sublayer with significant pores, as similar to the M-1 membrane. Apparently, the structure of L-1 membrane indicates that the $7 \mathrm{wt} . \%$ of PVA solution still shows the skin layer. Thus, the acetic acid plays an important rule at the PVA membrane formation process to occur the pores in the skin layer. 


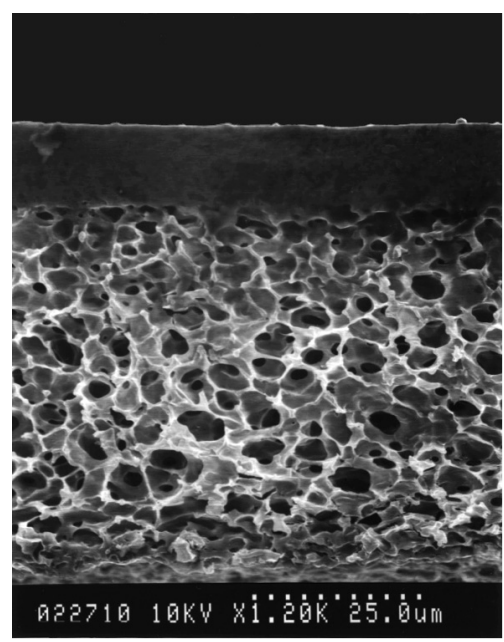

Fig. 10. The SEM photographs of cross-section of L-1 membrane.

\subsection{Membrane formation mechanism}

Obviously, the top layer and sublayer of M-1 membrane should have different formation mechanism, leading to different morphologies. In order to understand the asymmetric membrane formation mechanism, it is convenient to analyze the membrane as a two-layer structure [17]. On basis of above observation, the PVA could be precipitated by the absence of potassium hydroxide in the coagulant bath to exhibit a dense morphology. Therefore, when the casting solution was immersed into the coagulant bath, the toplayer was formed first at the casting solution-coagulant bath interface. Due to the salt effect of sufficiently high concentration of ions in the coagulant bath, the moment the casting solution and coagulant medium come into contact, water in the casting solution desolves into the coagulation bath. This means that the local polymer concentration increases and hence the viscosity also increases at the surface by the salt effect. Consequently, the increase in polymer concentration at the interface caused by the rapid outflow of water from the casting solution resulted in the formation of the dense skin layer as displayed by the M-1 membrane.

When the water in the casting solution diffuse out continuously by the salt effect of coagulant bath, the M-1 membrane will form a dense structure as M-1B membrane. Furthermore, from the SEM observation of M-1 membrane, the porous sublayer shows in Fig. 1b. The result could be caused by the coagulant medium through the skin diffusing into the sublayer to form the pores. Thus, the presence of $\mathrm{KOH}$ enhances the coagulant medium inflow to hasten the phase separation to induce the pores in the sublayer of M-1 membrane. This consists with the light transmission experiment in Fig. 3, suggesting that the precipitation rate increase with adding the $\mathrm{KOH}$ in the coagulant bath. The results of SEM observation suggest that the potassium hydroxide play an important role of the porous sublayer formation.

In formation of sublayer, precipitation of top layer creates an additional barrier to mass transfer between the sublayer and the coagulant bath. If the top layer structure is relatively compact, it will increase the mass transfer resistance of solvent from the sublayer of casting solution to the coagulation bath. Accordingly, after the dense top layer of the M-1 membrane is formed, water outflow rate from the sublayer of casting solution to the coagulation bath declines. At this time, when the coagulant medium (ions) diffuses through the top layer to work on its neighboring solvent in the sublayer, the nucleus of polymer-poor phase occurs. Nucleus grows to form a pore when coagulant medium can continually diffuse into it to induce neighboring solvent to diffuse into it. Thus, the polymer concentration of the polymer-rich phase surrounding the pore increases to form the pore wall. Although the action of the salt effect is highly localized, virtually all pores in the sublayer follow in this manner to some extent. Consequently, cellular morphologies supposed to occur in the entire sublayer supporting the dense top layer during the precipitation process.

From the above two-step mechanism model, a dense top layer is formed because solvent in the casting solution desolves into the coagulation bath before the coagulant medium diffuses into the casting solution. The dense top layer stops growing when enough coagulant medium diffuses into the sublayer solution to create pores. Therefore, the ratio of coagulant medium inflow to solvent outflow is of the utmost importance for the toplayer structure. If coagulant medium diffusing into the casting solution is so rapid to induce pores in the membrane surface, the result is a porous top layer.

On basis of above results, the hydrogen chloride and acetic acid additives are effective to induce pores 
formation in the skin layer as Figs. 4 and 6. However, the PVA membrane formation mechanism is different from those traditional ternary systems consisting of solvent, nonsolvent, and polymer. The coagulant bath is a mixture of water, $\mathrm{Na}^{+}, \mathrm{SO}_{4}^{2-}, \mathrm{K}^{+}$, and $\mathrm{OH}^{-}$. For simplicity, the relationship between casting solution with acid additive and coagulant medium is discussed.

From Fig. 4, the SEM observation shows that the pores occur in the top layer. As mentioned above, it is known that the strong acid $(\mathrm{HCl})$ dissolves in the casting solution to form rich $\mathrm{H}_{3} \mathrm{O}^{+}$ion. Therefore, when the casting solution with rich $\mathrm{H}_{3} \mathrm{O}^{+}$ion immerses into coagulant bath, the coagulant medium with rich $\mathrm{OH}^{-}$ion could have an enhancement in influx rate for acid-base equilibrium. Since the coagulant medium can be attracted by the rich $\mathrm{H}_{3} \mathrm{O}^{+}$ion in the casting solution, the coagulant medium inflow increases to hasten the phase separation to induce pores in the skin layer as shown in Fig. 4. This consists with the light transmission experiment, suggesting that the precipitation rate increase with rich $\mathrm{H}_{3} \mathrm{O}^{+}$ion in the casting solution. In addition, after the coagulant medium diffuses into the casting solution, the coagulant medium can attract the water of the casting solution to form the polymer-poor phase, then the pores occur.

The addition of a concentrated $\mathrm{HCl}$ in the PVA casting solution caused a large increase in $\mathrm{H}_{3} \mathrm{O}^{+}$ion concentration, which attracted a fast influx of coagulation medium, resulting in the formation of skinless membrane structure. The acetic acid is chosen to increase the $\mathrm{H}_{3} \mathrm{O}^{+}$ion in the casting solution (compare to $14 \mathrm{wt}$ \% of PVA solution) to regulate the influx rate of coagulant medium. Clearly, from SEM observation in Figs. 5 and 6 , the less $\mathrm{H}_{3} \mathrm{O}^{+}$ion concentration by adding acetic acid could modulate the thickness of skin layer to dictates the permselectivity of a membrane. The results also reveal that pores increase in the skin layer by the increase of the amount of acetic acid in the casting solution. This indicates that a casting solution with acetic acid is easier to phase separation. It is reasonable to attribute the fact that adding the acetic acid in the casting solution enhances the affinity between the casting solution and coagulant medium to occur phase separation easily. Since the increase of the amount of acetic acid in the casting solution, the $\mathrm{H}_{3} \mathrm{O}^{+}$ion concentration increases to enhance the coagulant medium inflow. This consists with the light transmission experiment, indicates that the precipitate rate increases with the increase of the amount of acetic acid. In conclusion, the casting solution with $\mathrm{H}_{3} \mathrm{O}^{+}$ ion could attract the coagulant medium inflow to induce pores in the skin layer. Thus, the above results suggest that controlling the $\mathrm{H}_{3} \mathrm{O}^{+}$concentration of casting solution could modulate the structure of PVA membrane. Obviously, the $\mathrm{H}_{3} \mathrm{O}^{+}$ion concentration in the casting solution plays an important role to control the influx rate of coagulant medium and the membrane structure.

\section{Conclusions}

The results of the present work suggest that the addition of acetic acid can change the PVA membrane structure and filtration properties. A mechanism describing the affinity between the casting solution and the coagulant medium is proposed to estimate PVA membrane structure by adding the acid in the complex system. Increasing the amount of acetic acid in the casting solution, the $\mathrm{H}_{3} \mathrm{O}^{+}$ion concentration increases to enhance the affinity between casting solution and coagulant bath. Therefore, the addition of acetic acid can enhance the inflow of the coagulant medium and the rate of phase separation, thus inducing a porous top layer. The results indicate that the membrane structure could be modulated by changing the amount of acetic acid in the polymer solution according to the requirements.

\section{Acknowledgements}

Acknowledgement is made to the donors of the Research Fund of Chinese Petroleum Company, administered by the National Science Council of the Republic of China.

\section{References}

[1] S. Loeb, S. Sourirajan, Sea water demineralization by means of an osmotic membrane, Adv. Chem. Ser. 38 (1963) 117.

[2] M. Mulder, Basic Principles of Membrane Technology, Kluwer, Dordrecht, The Netherlands, 1991.

[3] T.H. Young, N.K. Yao, R.F. Chang, L.W. Chen, Evaluation of asymmetric poly(vinyl alcohol) membranes for use in artificial islets, Biomaterials 17 (1996) 2139-2145. 
[4] T.H. Young, W.Y. Chuang, N.K. Yao, L.W. Chen, Use of a diffusion model for assessing the performance of poly(vinyl alcohol) bioartifical pancreas, J. Biome. Mater. Res. 40 (1998) 385-391.

[5] I. Sakurada, Polyvinyl Alcohol Fibers, Marcel Dekker, New York, 1985.

[6] R.E. Kesting, Synthetic Polymeric Membranes, Wiley, New York, 1985.

[7] L.P. Cheng, H.Y. Lin, L.W. Chen, T.H. Young, Solute rejection of dextran by EVAL membranes with asymmetric and particulate morphologies, Polymer 39 (1998) 2135-2142.

[8] T.H. Young, L.P. Cheng, H.Y. Lin, Interesting behavior for filtration of macromolecules through EVAL membranes, Polymer 41 (2000) 377-383.

[9] F.C. Lin, D.M. Wang, C.L. Lai, J.Y. Lai, Effect of surfactants on the structure of PMMA membranes, J. Membr. Sci. 123 (1997) 281-291.

[10] A.J. Reuvers, J.W.A. van der Berg, C.A. Smolders, Formation of membranes by means of immersion precipitation. Part I. A model to describe mass transfer during immersion precipitation, J. Membr. Sci. 34 (1987) 45-65.
[11] F.G. Paulsen, S.S. Shojaie, W.B. Krantz, Effect of evaporation step on macrovoid formation in wet-cast polymeric membranes, J. Membr. Sci. 91 (1994) 265-282.

[12] H. Strathmann, K. Kock, P. Amar, The formation mechanism of asymmetric membranes, Desalination 16 (1975) 179203.

[13] Y. Termonia, Molecular modeling of phase-inversion membranes: effect of additives in the coagulant, J. Membr. Sci. 104 (1995) 173-180.

[14] H. de Balmann, R. Nobrega, The deformation of dextran molecules causes and consequences in ultrafiltration, $\mathrm{J}$. Membr. Sci. 40 (1989) 311-327.

[15] S. Mochizuki, A.L. Zydeny, Dextran transport through asymmetry ultrafiltration membranes: comparison with hydrodynamic models, J. Membr. Sci. 41 (1992) 21-41.

[16] Y.S. Kang, H.J. Kim, U.Y. Kim, Asymmetric membrane formation via immersion precipitation method. I. Kinetic effect, J. Membr. Sci. 60 (1991) 219-232.

[17] T.H. Young, L.W. Chen, A two step mechanism of diffusion-controlled ethylene vinyl alcohol membrane formation, J Membr. Sci. 57 (1991) 69-81. 